Tropical Journal of Pharmaceutical Research, June 2009; 8 (3): 247-255

(C) Pharmacotherapy Group,

Faculty of Pharmacy, University of Benin,

Benin City, 300001 Nigeria.

All rights reserved.

Research Article

Available online at http://www.tjpr.org

\title{
Optimization and Development of Swellable Controlled Porosity Osmotic Pump Tablet for Theophylline
}

\author{
B. Prakash Rao ${ }^{1 *}$ M. Geetha ${ }^{1}$, N. Purushothama ${ }^{2}$, Utpal Sanki ${ }^{3}$ \\ ${ }^{1}$ Department of Pharmaceutics, Visveswarapura Institute of Pharmaceutical Sciences, Bangalore, ${ }^{2}$ Strides Arco Lab \\ Limited, Bangalore, ${ }^{3}$ Department of Pharmaceutics, Government College of Pharmacy, Bangalore, India.
}

\begin{abstract}
Purpose: To develop swellable controlled porosity osmotic pump tablet of theophylline and to define the formulation and process variables responsible for drug release by applying statistical optimization technique.

Methods: Formulations were prepared based on Taguchi Orthogonal Array design and Fraction Factorial design for core and coating, respectively. The tablets were prepared by direct compression and wet granulation methods; spray coated with ethyl cellulose solution containing varying amounts of PEG 400 and plasdone. Drug release from the osmotic drug delivery system was studied using USP Type I paddle type apparatus. The membrane morphology of the delivery system was determined by scanning electron microscopy (SEM).

Results: Optimization results indicated that the release rate of theophylline from the swellable controlled porosity osmotic pump tablet is directly proportional to the levels of osmotic agent, solubilizing agent and pore former in the tablet core and the membrane, respectively. SEM showed the formation of pores in the membrane through which drug release occurred. The best formulation showed $98.2 \%$ drug release and complied with USP requirements.

Conclusion: The results confirmed that the factors responsible for drug release were osmotic agents (core) and pore former (membrane). Also, the preparation of swellable controlled porosity osmotic pump tablet was facilitated by coating the core tablet with pore forming agent, thus eliminating the need for the more expensive laser drilling.
\end{abstract}

Key words: Swellable, Controlled Porosity, Osmotic Pump Tablet, Taguchi Orthogonal design, Fraction factorial design, Osmotic agent, Pore former, Scanning electron microscopy.

Received: 9 Aug 2008

Revised accepted: 17 Jan 2009

*Corresponding author: E-mail: bs_prao@hotmail.com, bprao_1111@rediffmail.com; Fax: +91-80-26711851 


\section{INTRODUCTION}

In recent years, considerable attention has been focused on the development of novel drug delivery systems (NDDS) ${ }^{1}$. Once-daily controlled release preparation is often desirable ${ }^{2}$. However, drug release from oral controlled release dosage forms may be affected by $\mathrm{pH}$, gastric motility, and presence of food. One practical approach with a potential to overcome these disadvantages is the osmotic drug delivery system where osmotic materials have been used extensively in the fabrication of drug delivery systems $^{3}$. The historical developments of osmotic systems include seminal contributions such as the Rose-Nelson pump $^{4}$, the Higuchi-Leeper pumps ${ }^{5}$, the Alzet osmotic pump ${ }^{6}$, the elementary osmotic pump $(E O P)^{7}$ and the push-pull osmotic pump $^{8}$. The osmotic drug delivery systems suitable for oral administration typically consist of a compressed tablet core that is coated with a semipermeable membrane that has an orifice drilled on it by means of a laser beam. The rate at which the core absorbs water depends on the osmotic pressure generated by the core components and the permeability of the membrane coating. As the core absorbs water, it expands in volume, which pushes the drug solution or suspension out of the tablet through one or more delivery ports $^{9}$. To obviate the need for complicated laser drilling, tablets coated with a membrane of controlled porosity have been described. These membranes consist of a leachable material which dissolves upon contact with water, leaving behind the pores through which the drug solution is pumped out. However, due to the relatively low permeability of the dense coatings, osmotic delivery of drugs with moderate to low solubility is limited ${ }^{10}$.

Asthma is an inflammatory disease characterized by bronchial hyperresponsiveness that can proceed to lifethreatening airway obstruction ${ }^{11}$. Theophylline (THP), which was selected as a model poorly soluble drug, has been used in asthma and chronic obstructive pulmonary disease for over 60 years and remains one of the most widely prescribed drugs in the treatment of airway diseases worldwide as it is inexpensive ${ }^{12}$. THP (1.3-dimethylxanthine) is a member of the xanthine family, sometimes referred to as purine alkaloid, and seems to have the same precursor as the nucleic acid ${ }^{13}$. It has a molecular weight of 180.17 and $\mathrm{pK}_{\mathrm{a}}$ of 3.5 and $8.6^{14}$; it relaxes smooth muscles and relieves broncospasm ${ }^{15}$ by inhibiting the enzyme phosphodiesterase which degrades cyclic nucleotides intracellularly ${ }^{16}$. Theophylline may be a useful treatment for nocturnal asthma and a single dose of a slow-release theophylline preparation given at night may provide effective control of nocturnal asthma symptoms ${ }^{17}$.

In this study, an attempt was made to design a simplified new swellable controlled porosity osmotic system for the delivery of a poorly soluble drug that eliminates the need for complicated and expensive laser drilling. This device is known as swellable controlled porosity osmotic pump (SCPOP). The study involves the use of Taguchi Orthogonal Array $\operatorname{design}^{18,19}$ and fraction factorial design ${ }^{18,20}$ for core and membrane formulation, respectively, and was intended to determine the effect of different independent variables on dependent (response) variables. In these systems, the hydrostatic force were produced by osmotic agents and polymer swelling force concurrently to drive the drug out of the system through the pores created by the pore-forming agent in the membrane coating after exposure of the system to water. In order to optimize release rate from the osmotic devices, the data from in vitro release studies were subjected to analysis of variance (ANOVA), and polynomial equations were developed to determine the quantitative relationship between dependent and independent variables by using Design Expert software. (Stat-ease Inc, Minneapolis, USA) 


\section{EXPERIMENTAL}

\section{Materials}

The theophylline (THP) and croscarmellose sodium (CCS) were obtained as gifts from Microlabs Pvt Ltd, Bangalore, India. Xanthan gum, plasdone S630, sodium lauryl sulphate (SLS), microcrystalline cellulose (MCC), ethyl cellulose, polyethylene glycol 400 (PEG 400), tartaric acid, sorbitol and triacetin were also obtained as gifts from Strides Arco Labs Pvt Ltd, Bangalore, India. All other chemicals used in the study were of analytical grade.

\section{Methods}

\section{Formulation Development}

Taguchi orthogonal array design ${ }^{18,19}$ was inculcated to develop formulations as outlined in Table 1. It is a large screening design that utilizes two-, three-, and mixed-level fractional factorial formats.

\section{Tablet production}

Core tablets of THP were prepared by both direct compression and wet granulation. In the direct compression method, all the ingredients were weighed accurately, as per Table 1, screened through a sieve of aperture size $250 \mu \mathrm{m}$ and blended for $5 \mathrm{~min}$ using double cone blender (Rimek Kalveka HD-410 AC, Gujarat, India) at $100 \mathrm{rpm}$ to get a uniform mix. Magnesium stearate and talc were added and blended for $2 \mathrm{~min}$.

In the wet granulation method, the drug was mixed with all the excipients except the binding and solubilizing agents and passed through sieve of aperture size $250 \mu \mathrm{m}$. The blend was mixed for 5 min using a double cone blender (Rimek Kalveka HD-410 AC, Gujarat, India.) at $100 \mathrm{rpm}$. The mixture was granulated with a granulating fluid prepared by dissolving the binding and wetting/solubilising agents in water. The resulting wet mass was passed through a sieve of aperture size $710 \mu \mathrm{m}$ and the granules were dried at $50{ }^{\circ} \mathrm{C}$ for $15 \mathrm{~min}$. The granules were then screened through a sieve of aperture size $355 \mu \mathrm{m}$, and blended with magnesium stearate and talc.

The granules obtained by both methods were compressed at a pressure of 6 tons in a laboratory press (Rimek RSB-4, Minipress, Gujarat, India) fitted with two sizes of concave punch sets - 10 and $12 \mathrm{~mm}$ diameter, respectively.

\section{Measurement of tablet thickness}

The thickness of ten tablet cores per batch was measured with electronic digital calipers (Aerospace, China) and mean thickness was calculated.

\section{Assay of theophylline}

The theophylline content of each tablet formulation was analyzed spectrophotometrically (Shimadzu UV-1601) at $271 \mathrm{~nm}$ based on the crushed material from 5 randomly selected tablets from each batch. The tablet material was dissolved in $0.1 \mathrm{M}$ $\mathrm{HCl}$ and appropriately diluted with the same medium to yield a concentration that falls in the Beer's range of $2-16 \mu \mathrm{g} / \mathrm{ml}$. The drug content was calculated using the formula in Eq 1.

$X=Y-0.019 / 0.0558$

where $X=$ concentration $(\mu \mathrm{g} / \mathrm{ml})$ and $\mathrm{Y}=$ absorbance.

\section{Coating of tablets}

Coating formulations were designed based on fraction factorial design. This design reduces the number of experiments required, compared with Factorial Design (FD), especially when the numbers of factors are high. The higher and lower levels of independent variables selected are described in Table 2. Dependent variables selected for the study include \% drug release at $24 \mathrm{~h}$. Core formulation F1 was selected to optimize the coating formula. 
Table 1: Taguchi orthogonal array design for core tablet formulations*

\begin{tabular}{lllllllll}
\hline Ingredient $(\mathrm{mg})$ & $\mathrm{F} 1$ & $\mathrm{~F} 2$ & $\mathrm{~F} 3$ & $\mathrm{~F} 4$ & $\mathrm{~F} 5$ & $\mathrm{~F} 6$ & $\mathrm{~F} 7$ & F8 \\
\hline Plasdone & 30 & 30 & 5 & 30 & 5 & 5 & 5 & 30 \\
CCS & 5 & 5 & 50 & 50 & 5 & 5 & 50 & 50 \\
Xanthum gum & 10 & 25 & 25 & 25 & 25 & 10 & 10 & 10 \\
Potassium chloride & 300 & 300 & 300 & 150 & 150 & 150 & 300 & 150 \\
Tartaric acid & 100 & 50 & 50 & 100 & 100 & 50 & 100 & 50 \\
SLS & 2.5 & 12.5 & 2.5 & 2.5 & 12.5 & 2.5 & 12.5 & 12.5 \\
Total (mg) & 572.5 & 547.5 & 557.5 & 482.5 & 422.5 & 347.5 & 602.5 & 427.5
\end{tabular}

${ }^{*}$ Compositions are given in terms of $\mathrm{mg}$ per tablet. Each formulation contained $100 \mathrm{mg}, 10 \mathrm{mg}, 10 \mathrm{mg}$, and $5 \mathrm{mg}$ of theophylline, MCC, magnesium stearate and talc, respectively. (CCS = crosscarmellose sodium; SLS = sodium lauryl sulphate, $M C C=$ microcrystalline cellulose)

Table 2: Fraction factorial design for 12 coating formulations*

\begin{tabular}{|c|c|c|c|c|c|}
\hline \multicolumn{2}{|c|}{ Ingredients } & $\begin{array}{c}\text { PEG } 400 \\
(\mathrm{ml})\end{array}$ & $\begin{array}{l}\text { Triacetin } \\
(\mathrm{ml})\end{array}$ & Sorbitol (g) & $\begin{array}{c}\text { Plasdone } \\
\text { (g) }\end{array}$ \\
\hline \multirow{12}{*}{ 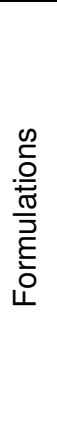 } & $\mathrm{C} 1$ & 0.707 & - & 1.2 & 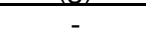 \\
\hline & C2 & -1 & 0.173 & 1.2 & - \\
\hline & C3 & 0.353 & - & - & 1.2 \\
\hline & C4 & 0.707 & - & 0.6 & . \\
\hline & C5 & 0.707 & - & - & 0.6 \\
\hline & C6 & - & 0.519 & - & 0. \\
\hline & C7 & 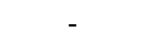 & 0.173 & 0.6 & 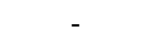 \\
\hline & C8 & 0.353 & - & - & 0.6 \\
\hline & C9 & - & 0.519 & 1.2 & . \\
\hline & C10 & 0.353 & - & 0.6 & - \\
\hline & C11 & 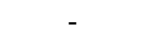 & 0.519 & - & 1.2 \\
\hline & C12 & 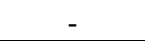 & 0.173 & - & 1.2 \\
\hline
\end{tabular}

${ }^{\star}$ Each formulation contained $2 \mathrm{~g}$ and $100 \mathrm{ml}$ of ethyl cellulose and ethanol, respectively.

A coating solution $(2 \% \mathrm{w} / \mathrm{v})$ of ethyl cellulose in ethyl alcohol (containing varying amounts of plasticizer and pore forming agent) was used to apply a semi permeable film on the tablets. The coating was carried out by spraying in a coating pan (Rimek Kalveka HD-410 AC, Gujarat, India) equipped with a hot air blower. The stainless steel pan was set a rotating speed of $25 \mathrm{rpm}$ and a spray rate of $5 \mathrm{ml} / \mathrm{min}$. The coated tablets were dried at $50{ }^{\circ} \mathrm{C}$ for $4 \mathrm{~h}$.

\section{In vitro release studies}

In vitro drug release of the formulations was carried out in a USP dissolution apparatus (paddle type) set at a rotating speed of 100 rpm and temperature of $37 \pm 1{ }^{\circ} \mathrm{C}$. The dissolution medium $(900 \mathrm{ml})$ was Simulated Gastric Fluid (SGF IP 2007, pH 1.2) for the first $2 \mathrm{~h}$ and Simulated Intestinal Fluid (SIF IP 2007, pH 6.8) thereafter. Samples (4 ml) were withdrawn at specified time intervals over a $24 \mathrm{~h}$ period and the medium was replenished with fresh dissolution fluid. The samples were suitably diluted, analyzed spectrophotometrically at $271 \mathrm{~nm}$ and drug release computed.

\section{Measurement of film thickness}

Following the completion of dissolution, the film was isolated from the tablets and dried at $40{ }^{\circ} \mathrm{C}$ for $1 \mathrm{hr}$. Thickness was measured at 
three different points on the film using electronic digital calipers (Aerospace, China.) and the mean values were taken.

\section{Optimisation studies}

The response values ( $24 \mathrm{~h}$ drug release) of coating formulations based on Fraction Factorial Design were subjected to analysis by response surface reduced quadratic model. The optimized coating formula was used to coat the 8 batches of tablets formulated according to Taguchi orthogonal array design. Core optimization was carried out based on Factorial model for 1, 4, 8, and $24 \mathrm{~h}$ drug release.

\section{Scanning electron microscopy}

The surface morphology of the optimized tablet film coating before and after dissolution was examined by scanning electron microscope. The samples were fixed on a brass stub using double-sided tape and then gold-coated in vacuum by a sputter coater. Scans were taken at an excitation voltage of $20 \mathrm{KV}$ in a JSM-840A scanning electron microscope fitted with JFC-1100E ion sputtering device (Jeol, Japan).

\section{RESULTS}

\section{Tablet thickness and drug content}

The thickness of tablet formulations F1 - F8 (10 $\mathrm{mm}$ diameter) and the optimized core tablet formulation (12 $\mathrm{mm}$ diameter) was in the range $3.87-5.92 \mathrm{~mm}$ for the former and $5.2 \mathrm{~mm}$ for the latter. Thickness depended on punch size and tablet weight; coefficient of variation (based on 20 tablets/batch) for each batch was less than $\pm 5 \%$, which indicates good thickness uniformity. Drug content was uniform within each batch and ranged from $97-110 \%$ of the theoretical value.

\section{Coating optimization}

The optimized coating formula in Table 3 obtained after optimization showed a weight gain of $2 \% \mathrm{w} / \mathrm{w}$, compared with the uncoated tablet. Film thickness of $0.065 \mathrm{~mm}$ and maximum in vitro release of $94.12 \%$ were observed.

Table 3: Composition of optimized formulations of coating and core

\begin{tabular}{ll}
\hline Ingredient & Quantity \\
\hline Coating & \\
Ethylcellulose & $2 \mathrm{~g}$ \\
Ethanol & $100 \mathrm{ml}$ \\
PEG 400 & $0.674 \mathrm{ml}$ \\
Plasdone & $1.10 \mathrm{~g}$ \\
& \\
Core (tablet) & per tablet $(\mathbf{m g})$ \\
Theophylline & 100 \\
Plasdone & 29.91 \\
CCS & 12.98 \\
Xanthan gum & 24.17 \\
KCl & 299.99 \\
Tartaric acid & 99.91 \\
SLS & 12.49 \\
Microcrystalline cellulose & 10 \\
Mg stearate & 10 \\
Talc & 5 \\
\hline
\end{tabular}

\section{DISCUSSION}

First, the coating formulation was optimized using Response Surface Reduced quadratic model based on core formulation F1.

\section{Influence of coating formulation variables on drug release}

The response values for percentage drug release at $24 \mathrm{~h}$ in the design run formulations were subjected to multiple analysis of variance. The model expressions were found to be significant with an $F$ value of 7.63 , Probability value (P-value) 0.0108 as the probability value is less than 0.1 (upper limit). To understand the mathematical relationship between independent and dependent variables studied, a polynomial equation (Eq 2) was generated using the Design Expert.

$\%$ drug release $(24 \mathrm{~h})=117.15+0.2973$ * $A$ $+24.8262{ }^{*} \mathrm{D}$ 
The independent factors PEG 400 (A) and plasdone (D) had positive influence on drug release, while triacetin (B) and sorbitol (C) showed antagonistic effect on the response and, therefore, were excluded from the model.

\section{Influence of plasticizer on drug release}

In order to study the influence of plasticizer level on drug release profile, different types and levels of plasticizers were used. A polynomial model shows that increment in the plasticizer (PEG 400) led to an increase in drug release. Since PEG 400 is a hydrophilic plasticizer, it could be leached out easily and increase the flux rate of fluid. The more PEG 400 incorporated into ethyl cellulose membrane, the lower the membrane permeability and drug release obtained due to the increased plasticity of the membrane. Another plasticizer, triacetin, is also a hydrophilic plasticizer but had negative influence on drug release; this could be due to its lower hydrophilicity compared to PEG 400.

\section{Effect of level of pore former}

To study the effect of level of pore forming agent, core compositions were coated with coating compositions containing different types and levels of pore formers (Table 2). As the levels of pore formers (plasdone and sorbitol) increased from lower to higher level, the release also increased. The increase in theophylline release could be due to formation of more pores after coming in contact with aqueous environment. Drug release is higher with plasdone than with sorbitol owing to the greater aqueous solubility of the former.

\section{Influence of core formulation variables}

The response values of $1,4,8$ and $24 \mathrm{~h}$ theophylline release were subjected to multiple analyses of variance using factorial model. For $1 \mathrm{~h}$ response, the model expressions were found to be significant with
$F(P$ - value) value of $0.7783(0.0464)$. The polynomial equation for the factorial model is given by $\mathrm{Eq} 3$.

$\%$ drug release $(1 \mathrm{~h})=13.7475+0.9175 * A+$ $1.505^{\star} E+0.055^{*} F$

For $4 \mathrm{~h}$ response, the model was found to be significant with $F$ ( $P$ - value) of 4.1088 (0.02073). The model is represented by Eq 4.

$\%$ drug release $(4 \mathrm{~h})=47.9725+0.3875^{*} \mathrm{~B}+$ $2.7175 * C+1.6475^{\star} \mathrm{E}+1.4525^{\star} \mathrm{F}+$ $0.9325^{\star} \mathrm{G}$

The model for the response $8 \mathrm{~h}$ drug release was found to be consequential as the $F(P$ value) is $0.3509(0.0185)$, and the model can be written as in Eq 5 .

$\%$ drug release $(8 h)=64.385+7.1525$ * $A+$ $0.13 * B+1.0125^{*} \mathrm{D}+2.5525^{*}$ $\mathrm{E}+1.135^{\star} \mathrm{F}$

At $24 \mathrm{~h}$ response, the model was found to be significant with $F$ ( $P$ value) of $6.65(0.049)$ as shown in Eq 6.

$\%$ drug release $(24 \mathrm{~h})=80.8562+0.3687{ }^{*} \mathrm{~A}$ $+5.1362{ }^{*} \mathrm{D}+3.4987^{*} \mathrm{E}$

Where $A=$ plasdone, $B=$ crosscarmellose sodium, $C=$ xanthan gum, $D=$ potassium chloride $(\mathrm{KCl}), \mathrm{E}=$ tartaric acid, $\mathrm{F}=$ sodium lauryl sulphate, and $\mathrm{G}=$ in process parameters.

In all the four responses, factors with positive coefficients influence response synergistically, while factors with negative coefficients show antagonistic effect on the response.

\section{Influence of osmotic agents}

To study the compositive influence of osmotic agents $(\mathrm{KCl}$ and tartaric acid), drug delivery systems were developed with different concentrations of $\mathrm{KCl}$ and tartaric acid. From the polynomial equations obtained for all responses, it was confirmed that increase in the concentration of osmotic agent increases drug release as the positive coefficient value found for factors $D$ and $E$ is high and their 
influence was seen in all the responses. When the coated tablet is exposed to an aqueous environment, water diffuses through the film coating (due to the active gradient of water), hydrating the core. The solvation of the osmotic agents creates osmotic pressure difference between the core contents and external environment results in greater theophylline release.

\section{Influence of swelling agents}

In the present study, swelling agents were used as drug entraining polymer, consisting of one or more swellable hydrophilic polymers (crosscarmellose sodium (factor B) and xanthan gum (factor $\mathrm{C}$ )) selected such that the polymeric swelling agent exhibits controlled swelling, the wall does not rupture or burst, and the desired rate of drug delivery can be obtained. However, swelling agents have less influence on all the responses (1, 8 , and $24 \mathrm{~h}$ ) except $4^{\text {th }} \mathrm{h}$ which was endorsed by polynomial models.

\section{Influence of wetting agent}

Since theophylline is a poorly soluble drug, a micellar solubilizer, sodium lauryl sulphate (SLS), was used to enhance drug solubility for faster release. In addition, SLS (factor F) has been used as an osmotic agent to create osmotic pressure; this dual nature caused increase in drug release.

\section{In vitro release study}

Formulations $\mathrm{F} 1+\mathrm{C} 3, \mathrm{~F} 1+\mathrm{C} 11$ and $\mathrm{F} 1+\mathrm{C} 12$ showed $81.62 \%, 75.85 \%$ and $79.14 \%$ drug release, respectively, as compared to other formulations, could be due to minimum level of plasticizer and maximum level of pore forming agent, but the release profile did not comply with USP limits for extended release capsules with 24 hour dosing interval ${ }^{21}$ (see Table 4). In order to achieve USP release levels, responses ( $24 \mathrm{~h}$ release) from all the coating runs were included in the optimization design (i.e., Response surface reduced quadratic model) and the best solution for coating formulation was obtained. Optimized coating formula with $\mathrm{F} 1$ core formulation exhibited $94.12 \%$ drug release which is near to the predicted value of $99.84 \%$, although it did not comply with USP limits except for $1^{\text {st }}$ and $2^{\text {nd }} \mathrm{h}$. The optimized coating was used to optimize tablet core runs of Taghuchi Orthogonal Array design. Formulations F1, F3, F8 showed $94.12 \%, 85.13 \%$ and $70.76 \%$ release respectively in relation to other formulations. The reason could be the elevated levels of osmotic agent (plasdone) which modifies crystalline nature of the drug, thus facilitating drug release, and the increased levels of solubilizing and swelling (crosscarmellose sodium) agents as they increase solubility and delivery rate, respectively; this is true for formulations $F 1$ and F8. However, in the case of formulation $\mathrm{F} 3$, the sudden increase in drug release after $8 \mathrm{~h}$ was due to 'burst' effect. Responses of all design runs were added in the optimization model. The results of optimization indicate the significant effect of osmotic agents $(\mathrm{KCl}$ and tartaric acid), plasdone and solubilizing agent on drug release. The ultimate optimized formulation showed $94.02 \%$ with USP compliance in terms of release (see Table 4).

Table 4: Comparison of release profile of USP theophylline extended release capsules (labeled for $24 \mathrm{~h}$ dosing) with optimized SCPOP formulation

\begin{tabular}{lll}
\hline & $\begin{array}{l}\text { Release profile of } \\
\text { theophylline } \\
\text { extended release } \\
\text { capsules labeled } \\
\text { Time } 24 \mathrm{~h} \text { dosing } \\
\text { (h) }\end{array}$ & $\begin{array}{l}\text { Release } \\
\text { profile of } \\
\text { optimized }\end{array}$ \\
& $\begin{array}{l}\text { SCPOP } \\
\text { formulation } \\
\text { limit) }(\%)\end{array}$ & $(\%)$ \\
\hline 1 & $5-15$ & 15.98 \\
2 & $12-30$ & 30.56 \\
4 & $25-50$ & 52.04 \\
5 & $30-60$ & 59.9 \\
8 & $55-75$ & 75.88 \\
\hline
\end{tabular}




\section{Scanning electron microscopy}

Ethyl cellulose membranes obtained before and after dissolution, were studied by SEM. After the completion of dissolution, exhausted membrane contained plasticizer (PEG 400, $38.10 \%$ ) and pore former (plasdone, 55.32 $\%$ ) showed a microporous region surrounded by a macroporous region (Fig 1).
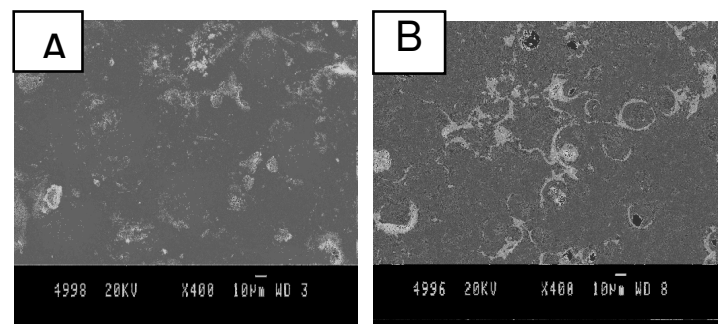

Fig 1: Scanning electron microphotographs of coating membranes of optimized formulation before dissolution $(\mathrm{A})$ and after dissolution $(\mathrm{B})$

\section{CONCLUSION}

Taguchi orthogonal design (for tablet core) and fraction factorial design (for coating) were adequately applied to study the effect of different formulation variables on the release profile to select optimized formulations. Membranes were found to develop pores/channels after coming in contact with aqueous environment; the number of pores being dependent on the initial level of the pore former in the membrane. Finally, it can be concluded that preparation of osmotic pump tablet can be simplified by coating the core tablet with a pore-forming agent which is likely to be more cost-effective than laser drilling.

\section{REFERENCES}

1. Shokri J, Ahmadi $P$, Rashidi $P$, Shahsavari $M$, Rajabi-Siahboomi A, Nokhodchi A. Swellable elementary osmotic pump (SEOP): An effective device for delivery of poorly watersoluble drugs. Eur J Pharm Biopharm, 2008; 68: 289-297.

2. Liu L, Che B. Preparation of monolithic osmotic pump system by coating the indented core tablet. Eur J Pharm Biopharm, 2006; 64: 180 84.

3. Khan MA, Sastry SV, Vaithiyalingam SR, Agarwal $V$, Nazzal S, Reddy IK. Captopril gastrointestinal therapeutic system coated with cellulose acetate pseudo latex: evaluation of main effects of several formulation variables. Int J Pharm, 2000; 193: 147-156.

4. Rose S, Nelson JF. A continous long-term injector. Aust J Exp Biol Med Sci, 1955; 33: 415-420.

5. Theeuwes $F$, Swanson $D$, Wong $P$, Bonson $P$, Place V, Heimlich K, Kwan KC. Elementary osmotic pump for indomethacin. J Pharm Sci, 1982; 72: 253-258.

6. BittnerB, Thelly Th, Isel H, Mountfield RJ. The impact of co-solvents and the composition of experimental formulations on the pump rate of the ALZET osmotic pump. Int J Pharm, 2000; 205: 195-198.

7. Higuchi T, Leeper HM. Osmotic dispenser with means for dispensing active agent responsive to osmotic gradient, 1976; US Patent No. 3,995, 631.

8. Prabakaran $D$, Singh $P$, Kanaujia $P$, Jaganathan KS, Rawat A, Vyas SP. Modified push-pull osmotic system for simultaneous delivery of theophylline and salbutamol: development and in vitro characterization. Int J Pharm, 2004; 284: 95-108.

9. Thombre AG, Appel LE, Chidlaw MB, Daugherity $P D$, Dumont $F$, Evans LAF, Sutton SC. Osmotic drug delivery using swellable-core technology. J Cont Rel, 2004; 94: 75-89.

10. Garg $A$, Gupta $M$, Bhargava HN. Effect of formulation parameters on the release characteristics of propranolol from asymmetric membrane coated tablets. Eur $J$ Pharm Biopharm, 2007; 67: 725-731.

11. Mullett WM, Lai EPC. Rapid determination of theophylline in serum by selective extraction using a heated molecularly imprinted polymer micro-column with differential pulsed elution. $J$ Pharm Biomed Anal, 1999; 21: 835-843.

12. Barnes PJ. Theophylline: New Perspectives for an Old Drug. Am J Respir Crit Care Med, 2003; 167: 813-818.

13. Zhang KE, Huang $H, W u X$, Cai $R$, Korenaga $T$. Stopped-flow kinetic study on intermediate of theophylline oxidation reaction via rapidscanning uv/vis spectroscopy. Anal Sci, 1997; 13: $475-478$.

14. Hansch C, Sammes PG, Taylor JB. Comprehensive medicinal chemistry. Oxford, England, Pergamon Press, Vol. 6, 2005, pp 895.

15. Ansari $M$, Kazemipour $M$, Shahriar $M$. Simultaneous quantitation of theophylline and guaifenesin in syrup by HPLC, derivative and derivative ratio spectrophotometry for quality control purpose. Iranian J Pharmacol Ther, 2006; 5: 67-72.

16. Tripathi KD. Essentials of medical pharmacology. New Delhi, Jaypee brothers medical Publishers, $6^{\text {th }}$ edition, 2008, pp 220. 
Rao et al

17. Barnes PJ, Pauwels. Theophylline in the management of asthma: time for reappraisal? Eur Respir J, 1994; 7: 579 - 591.

18. Singh B, Kumar $R$, Ahuja N. Optimizing drug delivery system using systematic "design of experiments" part I fundamental aspects. Critical reviews in therapeutic drug carrier systems.2004; 22: 27-105.

19. Huang YT, Tsai TR, Cheng CJ, Cham TM, Lai TF, ChuoWH. Formulation Design of a Highly Hygroscopic Drug (Pyridostigmine Bromide) for its Hygroscopic Character Improvement and Investigation of In Vitro/In Vivo Dissolution Properties Drug Dev and Ind Pharm, 2007; 33: $403-416$

20. Loukas YL. Fractional factorial design via fold over: application to optimization of novel multicomponent vesicular systems. Analyst, 1997; 122: 1023-7.

21. US Pharmacopoeia and National Formulary, ed 24, United Pharmacopeial Convention, Inc., Rockville, 2000. 1630-1. 